\title{
LOS INDIGENISMOS EN ECUADOR: DE PATERNALISMOS Y OTRAS REPRESENTACIONES
}

\author{
Fredy Rivera Vélez *
}

El panorama político mundial expresa actualmente una serie de confrontaciones sociales en las que el fenómeno étnico aparece como factor nodal de su dinámica. Resulta en igual forma evidente que en muchos de esos conflictos se presenta una lógica o denominador común: el cuestionamiento a la ecuación Estado-nación como fórmula política que ha regido el ordenamiento, integración y construcción de las sociedades en los tiempos modernos. Es innegable que asistimos a un proceso de revitalización de las identidades étnicas y regionales en tanto formas de movilización y acción política de importantes conglomerados poblacionales que dan cuenta de la pérdida de ese horizonte integrador del estado nacional. Y es que desde los momentos iniciales o fundacionales de varios estados-nación latinoamericanos se presentó un proceso de construcción nacional que contiene un complejo juego de representaciones e ima-

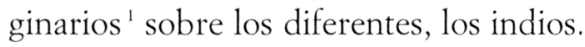

El proceso de construcción nacional implicó la ejecución de una serie de relaciones asimétricas de explotación y poder, de acceso diferencial a recursos y servicios, de un desarrollo regional desigual, de la instauración de privilegios y prebendas para un determinado sector poblacional, pero desde un punto de vista ideológico, existieron una serie de prácticas identitarias que incluyeron lo supuestamente homogéneo y excluyó las diferencias. «El control, manipulación y representación del pasado, la producción y celebración de símbolos y santuarios nacionales, así como una figuración del «otro» mayoritario, se convierten en un proceso central en el establecimiento de la nación-estado» ${ }^{2}$.

La situación señalada adquiere mayor importancia y complejidad cuando se trata de países con fuerte presencia indígena en su población. Guatemala, Perú, Bolivia, México, Ecuador, entre otros, son países donde no han desaparecido un conjunto de políticas de exclusión y formas de representación elaboradas sobre los grupos indígenas a pesar del desarrollo institucional y legal de los estados. Al contrario, las representaciones étnicas se han modificado paulatinamente de acuerdo a las distintas fases históricas y políticas que ha asumido el estado-nación. En ese juego de representaciones, las políticas indigenistas y neoindigenistas llevadas a cabo por los gobiernos; las acciones organizativas de los partidos de distinto signo que han privile- giado las dimensiones clasistas como espacios identitarios para los indígenas; y, la serie de paternalismos a los que se ha recurrido para incorporar culturalmente al indio y al negro en la sociedad blanco mestiza, son parte de un prolongado y complicado juego de imágenes, imaginarios y representaciones elaboradas sobre los pueblos indígenas y negros desde los sectores no indios.

Se trata de un proceso de construcción nacional en sí mismo contradictorio ya que implica, por un lado, la difusión legal de las nociones de ciudadanía, participación e igualdad constitucional, típicos de la democracia liberal y, por otro lado, en la práctica cotidiana, la ejecución de la intolerancia étnico-cultural hacia los pueblos indígenas y negros. En esa construcción, el papel desempeñado por el estado ha sido de vital importancia, pues ha moldeado intencionalmente a la nación a partir de agregados de etnias, poblaciones, regiones y grupos y, por medio de una retórica que peca de extremadamente voluntarista, ha supuesto una voluntad colectiva mayoritaria de individuos que expresaron su deseo de vivir juntos en un mismo espacio. Empero, el buen sentido común y un poco de historia indican claramente que esta voluntad de vivir juntos y constituirse en estado nacional es una imaginación, por lo menos desde el punto de vista sociológico en países en que los grandes sectores indígenas y negros no sólo no compartieron esta supuesta voluntad sino que expresaron y expresan permanentemente su absoluta disconformidad ${ }^{3}$.

En el Ecuador contemporáneo esa disconformidad política ha sido canalizada por el movimiento indígena. A raíz de los levantamientos de 1990 y 1994 que paralizaron al país, se ha abierto un panorama expectante para la

Profesor investigador de Flacso Sede Ecuador. Editor de la Revista Ecuador Debate del CAAP.

1. El papel de los imaginarios en la construcción de las naciones ha sido largamente analizado en la obra clásica de Benedict Anderson Comunidades Imaginadas. FCE, México, 1993.

2. Muratorio Blanca. «Discursos y Silencios sobre el Indio en la Conciencia Nacional» en: Imágenes e Imagineros. Representaciones de los Indios ecuatorianos, Siglos XIX y XX FLACSO, Quito, 1994, p. 17.

3. Varese Stefano. «Movimientos indios de liberación nacional y Estado Nacional» en: La Diversidad Probibida. Resistencia Etnica y poder de Estado. Colmex, México, 1989. 
política nacional pues ha permitido observar las diferentes posiciones políticas de los diversos sectores de la sociedad. De hecho, su incidencia ha replanteado y cuestionado profundamente las bases constitutivas de cierta figura de Estado-nación como fórmula integradora de la sociedad, más aun cuando en los actuales momentos se discuten una serie de reformas constitucionales relacionadas con el problema mencionado.

En ese contexto y más allá de que el movimiento indígena se haya constituído en actor político de singular importancia al tener voz propia en el Congreso Nacional, lo más importante radica, desde esta perspectiva analítica, en que sus actuaciones políticas generaron la fractura del conjunto de representaciones e imaginarios que sobre los indios habían elaborado la sociedad y el estado ecuatoriano para lograr la tan ansiada identidad nacional. Todo ello ha promovido una serie de debates en diversos espacios de la sociedad ecuatoriana, situación que no puede ser soslayada ya que conduce a una resignificación de lo que se entiende por identidad nacional, pero sobre todo, a un proceso de redefinición del estado-nación ecuatoriano como instancia integradora de la diversidad étnico-cultural.

\section{LOS INDIOS Y EL ESTADO-NACIÓN}

Para lograr que las concepciones de nación y cultura uniforme se extiendan, ha sido necesario que los grupos de poder y el Estado enfaticen reiteradamente la existencia de un solo modelo cultural basado en el mestizaje, una lengua y un proyecto societal de futuro. De esa forma, el estado se mimetiza con la nación, que aparece entonces como una supercomunidad homogénea, sin contradicciones aparentes y como el principio central de referencia para la legitimidad de los estados en tanto constituye una garantía de la homogeneidad cultural y étnica de las poblaciones reunidas dentro de su ámbito de acción y control social. Dicho de otro modo, la nación se presenta como un principio de identidad que unifica lo que fue con lo que es, pero también delimita la perspectiva de lo que ha de ser, es decir, se presenta como un sentido trans-temporal de existencia colectiva.

En ese orden de cosas, la identidad nacional aparece como un manto protector que avala la construcción homogénea de la nación, como un vehículo que condensaría las diversas expresiones culturales y étnicas de la población de una determinada sociedad y, como parte componente del gran supuesto voluntarista de integración nacional que, en el caso ecuatoriano, viene pregonándose desde finales del siglo pasado a través de postulados decimonónicos y liberales del sujeto-indio como contraimagen del proyecto de ciudadanía blanco mestiza ${ }^{4}$. Proceso ideológico que de forma sutil ha calado profundamente en la mentalidad y en el sistema político de los ecuatorianos.

De ahí precisamente deviene la idea de nación como un sistema identitario basado en una serie de representaciones elaboradas sobre los «otros», los indios y negros que se concreta en prácticas centralizadoras y excluyentes al restringir la posibilidad de participación decisoria a los grupos poblacionales que mantienen identidades y realidades diferenciadas; en la igualdad formal de todos los miembros de la comunidad nacional, mientras se mantiene y reproduce la desigualdad real que existe entre ciertos grupos socioculturales y otros sectores dominantes de la sociedad que se sienten portadores de la verdadera nacionalidad; en la negación o el rechazo de la diferencia cultural y linguística, y la búsqueda declarada de una homogeneidad que privilegia un patrón cultural respecto a los demás bajo el supuesto de que el ideal e imaginario social escogido es la garantía de la unidad nacional. En ese contexto ideológico, unidad nacional y pluralidad sociocultural se presentan como instancias antitéticas.

\section{EL JUEGO DE LAS REPRESENTACIONES: LAS CARAS DEL PATERNALISMO Y LA INTEGRACIÓN}

Durante largo tiempo, el problema de la integración de los pueblos indígenas en la construcción de la nación fue interpretado desde posiciones que enfatizaban, por una parte, un tipo de voluntarismo, sociologista, que se interrogaba acerca de cúal es la clase que realiza la nación; y, por otra parte, la infaltable tendencia economicista, que encontraba en la realización del mercado interno nacional la causa primera de la existencia de la nación.

Si bien estas posturas interpretativas han aportado elementos importantes para pensar el fenómeno de la nación como un determinado resultado histórico, existen otras dimensiones conceptuales que deben ser incorporadas para resaltar la idea de que la construcción imaginaria y pretendidamente homogeneizante de la nación, está sustentada en un conjunto de representaciones excluyentes elaboradas sobre los «otros», los indios, los negros, los diferentes.

Bajo esa perspectiva, las representaciones colectivas son actos de producción de espacios socio-ideológicos dentro de los cuales se proyecta la autorepresentación de la sociedad como el "nosotros social", como el ideal de sociedad, como un ser "que va más allá de los individuos y como las instancias que generan históricamente imaginarios a las instituciones e individuos dentro de la sociedad, es decir, el representar/decir sociales, incorporan sólidos marcos de pensamiento -leyes, tiempo, espacio, valores, totalidad etc. $-\mathrm{y}$ son portadoras de significados sociales en la conciencia colectivas. Para Bordieu, las representaciones sociales son mecanismos de percepción y apreciación, de conocimiento y reconocimiento en que los agentes invierten sus intereses y sus presupuestos. Estos actos son también representaciones objetales que funcionan como signos, emblemas, como estigmas y también poderes, es decir, son estrategias interesadas de manipulación simbólica que persiguen determinar la representación mental que

4. Para un mayor desarrollo de este punto de vista ver: Guerrero Andrés, La semántica de la dominación. El concertaje de indios, Libri Mundi, Quito, 1992.

5. Beriain Josexto, Representaciones colectivas y proyectos de modernidad, Antropos, Barcelona, 1990. 
los demás pueden formarse de dichas propiedades y de sus portadores 6 .

Por lo tanto, las representaciones son productos y valores culturales y políticos transmitidos de generación en generación entre la población blanco-mestiza, alimentados y ratificados mediante experiencias cotidianas desde la tierna infancia al frecuentar indígenas en la ciudad y el campo. Conforman esquemas mentales que guían clasificaciones de la población y posibilitan el diseño de estrategias de violencia simbólica que desvaloriza al sometido y valora a los opresores $^{7}$.

Esta serie de ideas son importantes en la medida que aportan elementos claves para ir definiendo el pensamiento identitario nacional a lo largo de la historia y nación ecuatoriana donde ha prevalecido la noción de la integración ${ }^{8}$. Así, para lograr concretar el proyecto e idea de nación criolla-mestiza se desarrollaron una serie de nociones y representaciones paternalistas, indigenistas y neoindigenistas. Por ejemplo, el liberalismo, en su lucha por constituirse en ideología dominante, va forjando una representación mental del indio que lo ubica como sujeto irracional por medio de la fórmula: indios=barbarie=animalidad $=$ pasividad irracional, ante el cual valen todos los esfuerzos civilizatorios de lengua castiza y cultura ecuatoriana ${ }^{9}$. Es así como se prolonga las relaciones de dominación étnica sustentadas por los sectores dominantes blanco mestizos en su intento por construir la nacionalidad ecuatoriana y, aunque presente una máscara de modernización, la propuesta liberal ve a los indígenas como una población sujeta a ser redimida y civilizada bajo causes paternalistas.

Este tipo de representaciones paternalistas, con variados matices, son las que han estado presentes a lo largo del siglo que decurre en las mentalidades de la sociedad ecuatoriana en su esfuerzo por construir la tan ansiada nación e identidad nacional a través de procesos socioculturales y políticos que enfatizan la integración. En términos concretos, los paternalismos son una serie de acciones y políticas concebidas para ser aplicadas a los «otros», no suponen una consideración de las especificidades identitarias y los intereses organizativo-históricos de esos otros, sino que se fundamentan en una negación profunda de sus capacidades para determinar lo que les es conveniente o no. En esa perspectiva, los paternalismos han tenido y tienen un gran espectro de presentaciones. Van desde el más fino altruismo desarrollado por los sectores hegemónicos blanco mestizos que, por una extraña mezcla de conciencia misericorde y verguenza histórica, se sienten culpables por las condiciones de explotación y oprobio en el que se hallan los indígenas; pasan por una serie de acciones ejecutadas por la iglesia y sus organismos asistenciales en pos de redimir, salvar y enaltecer al indio; y, llegan hasta el sutil enmascaramiento revolucionario-proletario, planteado por algunas corrientes de izquierda que vieron en los indígenas al pueblo perdido que debía ser conducido de la mano a un horizonte de futuro donde prevalezca una sociedad justa, igualitaria y sin explotación.

De esa gama de presentaciones paternalistas, es pertinente centrarnos brevemente en los denominados indige- nismos, neoindigenismos y en las prácticas políticas de la izquierda marxista, el paternalismo clasista.

\section{LOS INDIGENISMOS}

El indigenismo, que es el tipo de política más conocida, extendida y aplicada por diversos países en el medio latinoamericano respecto al tratamiento de «lo indio» o de «sus indios», surge en un contexto de alta convulsión social promovido por la expansión de las corrientes liberales de pensamiento filosófico y político; en el punto de inflexión del colonialismo mundial como fórmula política dominante que ordenaba los destinos del sistema económico internacional; y, en la fase inicial de ascenso y expansión de las formas capitalistas de producción dentro de las débiles y poco cohesionadas naciones latinoamericanas.

Visto generalmente, el indigenismo latinoamericano reconoce la existencia del pluralismo étnico y la necesidad consecuente de elaborar políticas especiales para los pueblos indígenas a través de variadas acciones. Estas acciones debían ser protectoras, porque se concibe al indígena como un individuo económica y socialmente débil -un menor de edad-, tenían que ser corporativas, porque era indispensable la integración total de los indios bajo la forma de ciudadanía en la vida económica y social de cada país, y, debían ser estimulantes de los aspectos considerados positivos de las culturas indígenas para lograr su desarrollo integral en el marco de la comunidad moderna, nacional y occidental.

En este tipo de percepción, la cuestión indígena constituye un problema a resolver en la medida que su solución está asociada a la tarea de conformar la nación como un todo integrado.

Esta visión evolucionista y etnocéntrica inicial del indio es corregida con posterioridad mediante el desarrollo de posturas indigenistas denominadas «integracionistas» que se inauguran a raíz del Congreso Indigenista de Patzcuaro en 1940. Básicamente, el integracionismo trata de generar una compatibilidad entre integración de los indios a la sociedad nacional moderna, dotándoles de todos los instrumentos civilizados necesarios y conservando las

6. Bordieu Pierre «La Identidad como representación» en: Ce que parler veut dire Fayard, Paris, 1982, p 135.

7. Guerrero Andres «Una Imagen Ventrílocua: El discurso liberal de la «desgraciada raza indígena» a fines del Siglo XIX» en: Imágenes $e$ Imagineros. Representaciones de los Indigenas Ecuatorianos. Siglos XIX y XX FLACSO, Quito, 1994, p. 231.

8. No es la intención de este trabajo abordar una revisión pormenorizada de las representaciones que sobre los indios ha construido la historia ecuatoriana. Un detalle de este punto en: Rivera Fredy, Indios, Imaginario nacional y Politica en el Ecuador, Tesis Mtr, FLACSO, México, 1994.

9. Construcción mental que impregna las interpretaciones políticas y jurídico-sociológicas, coloca bajo cierta iluminación las percepciones de la realidad y, al hacerlo, elabora una opinión pública generalizada. Por eso, el liberalismo para legitimarse como movimiento político y corriente ideológica define el sujeto y el objeto de la opresión, elabora las causas e imágenes de tal situación y, plantea las alternativas de solución para arribar al objetivo perseguido: redimir al indio pasivo y llevarlo de la mano hacia la civilización». Guerrero Andrés. La Semántica de la Dominación El concertaje de indios. Libri Mundi, Quito, 1991 p 334. 
matrices culturales que les son característicos a dichos grupos étnicos. En este caso, el proceso de integración nacional pensado no se sustenta en dinámicas compulsivas destinadas a la cultura indígena, sino más bien en la recuperación y respeto de las especificidades culturales de las etnias. De esa forma, los pueblos indios son incitados a invertir sus propios esfuerzos para lograr su propio mejoramiento y su integración a la nación, para que efectivamente se conviertan en partes integrantes de la misma ${ }^{10}$. De esa manera, el integracionismo, bajo el manto protector del discurso racional se convierte oficialmente en la política oficial de los estados nacionales latinoamericanos, entre los que el Ecuador no es la excepción.

Así, la dinámica del indigenismo integracionista resultó ser el instrumento más adecuado para la construcción de la tan ansiada nación blanco mestiza, ya que permitió transitar de acciones explícitamente destructivas de las culturas de los pueblos indígenas, hacia la adopción de un proyecto de largo aliento, basado en el efecto absorbente y asimilador de la cultura nacional dominante, lógica y práctica política que ha sido caracterizada como etnofagia ". Este tipo de prácticas y discursos indigenistas-integracionistas, al ser cuestionados por muchos sectores sociales, entre ellos el de un movimiento indígena que comenzó a tener un papel político importante en las décadas de los sesenta y setenta, sufre una matamorfosis tanto en el discurso como en la práxis: tal mutación devendrá en el neo indigenismo.

\section{EL NEOINDIGENISMO}

El neoindigenismo aparece como una tendencia ideológica aparentemente progresista que, criticando los afanes homogenizadores y unitarios del indigenismo integracionista tradicional, se caracteriza por postular la pluralidad o diversidad sociocultural de las formaciones nacionales a base de un sobredimensionamiento de la civilización india como proyecto societal global. Esta corriente, calificada como culturalista radical, presenta un discurso, el etnicismo, y una práxis, el etnopopulismo.

El etnicismo parte de una concepción abstracta y generalizante del fenómeno étnico que supone la existencia de una «esencia» étnica. En esta perspectiva, los grupos étnicos son entendidos como entidades invariantes y eternas, cuya particularidad más conspicua consiste en flotar por encima de los procesos históricos, ya que lo étnico es asumido como un fenómeno inmutable; de tal manera que, permaneciendo idénticos a sí mismos, los grupos indios podrán contar con las condiciones objetivas adecuadas para renacer y manifestarse plenamente. En otras palabras, nos hallamos frente a una interpelación ética de occidente basada en la superioridad de la civilización india ${ }^{12}$.

A juicio de los etnicistas, las sociedades indígenas son homogéneas, todos los miembros son integrantes de una solidaridad étnica que supera los intereses particulares de clase $y$, en tanto son iguales y colonizados, constituyen entonces una comunidad fraterna que se enfrenta a un enemigo común: el colonizador: El adversario se encuentra por fuera de los linderos comunitarios y entre los indios no existen posibilidades de reproducir los mecanismos de explotación; en caso de generarse este tipo de situaciones, la causa se ubica en el exterior y no en la dinámica interna de las comunidades indias. En ese contexto, la lucha política del indio para lograr reivindicaciones de toda índole está atravesada por un profundo proceso de concientización interna y a la espera de cualquier momento adecuado para desarrollar su proyecto civilizatorio ${ }^{13}$.

En síntesis, dado que los etnicistas presentan la historia nacional como un proceso de colonización donde se han enfrentado los buenos -indios- y los malos -occidentales-; donde la solución al problema indígena está mediatizado por el advenimiento de un orden futuro, regentado por la civilización milenaria y; donde, las aspiraciones inmediatas de los indígenas organizados tienen que ser tratadas a base de un cambio en la moral del estado y sociedad en conjunto por medio de modificaciones de ley, aparatos administrativos y organismos pertinentes, dichas posturas etnicistas, construyeron, indirectamente, el terreno propicio para que el mismo estado a quien pretenden combatir y la sociedad blanco mestiza a la cual intentan desplazar, respondieran con un tipo de práctica que ha sido calificada como etnopopulista, pues si bien abren espacios de participación a sus representantes -proceso que a más de ser envolvente y de generar una burocracia india separada de sus comunidades-, también establecen paralelamente los límites institucionales para tal actividad; es decir; se participa en los espacios de dirección que altruístamente abre el estado nacional sin plantear la existencia de un problema étnico-nacional. Este último aspecto es de suma importancia para ubicar a las políticas neoindigenistas que, en el caso ecuatoriano, para asegurar y controlar su aporte a la sociedad, los gobiernos propusieron la protección, conservación e investigación de las «culturas vernáculas», tratando de que la aculturación de sus miembros no implique la renuncia de sus propias identidades culturales, en el implícito de integrarlos -conjugando tradición y modernidad- en los términos de la ideología dominante que enfatiza el concepto de ecuatorianidad como panacea de unicidad e identidad nacional ${ }^{14}$.

10. Aguirre B. Gonzalo. «Un postulado de Política Indigenista» en: Obra Polémica, SEP-INAH, México, 1976 p. 27.

11. «La etnofagia expresa el proceso global mediante el cual la cultura de la dominación busca engullir o devorar a las múltiples culturas populares, principalmente en virtud de la fuerza de gravitación que los patrones nacionales ejercen sobre las comunidades étnicas. No se busca la destrucción mediante la negación absoluta o el ataque violento de las otras identidades, sino su disolución gradual mediante la atracción, la seducción y la transformación». Diaz P. Héctor. Autonomia Regional. La Autodeterminación de los Pueblos Indios. México, Siglo XXI, 1992, p. 97.

12. Este tipo de argumentaciones las podemos hallar en el trabajo de Bonfil B. Guillermo y Rodríguez Nemesio. Las Identidades Probibidas. Situación y Proyectos de los Pueblos Indios de América Latina. SCA Project, México, 1981.

13. Concepciones parecidas han sido levantadas en el Ecuador hace pocos años. Para un mayor detalle ver: Ramon Galo. El Regreso de los Runas. Abya Yala-Comunidec, Quito, 1993.

14. Un estudio detallado de las políticas neoindigenistas en el Ecuador se encuentra en el trabajo de Ibarra Alicia Los Indígenas y el Estado en el Ecuador: La Práctica Neoindigenista. Abya Yala, Quito, 1992. 
En la práctica, el etnopopulismo instrumentaliza medidas modernizantes y contribuye a desmantelar algunos obstáculos que se oponen al desarrollo capitalista y a la acción política de los grupos hegemónicos, resultados muy contrarios a su discurso culturalista, milenario y radical. En esa dinámica, resulta evidente que el problema de la integración, tan duramente combatido, se convierta en el boomerang de los mismos etnicistas y sus postulados tengan matices velados del tradicional indigenismo.

Pero existe otro aspecto que debe ser destacado y es el que se relaciona con la recurrencia del juego de representaciones e imaginarios que se construyen sobre el indio. Si en el indigenismo paternalista y tradicional prevalecía una noción de indio atrasado, decadente, irracional e incivilizado, en esta nueva versión aparentemente radical, aflora la idea del buen salvaje, solidario, fraterno, milenario, apacible y aunque radical, participativo en los ámbitos de la sociedad y estado nacional.

\section{EL PATERNALISMO CLASISTA: LA IZQUIERDA Y LOS INDIOS}

Reconstruir una extensa discusión sobre las particularidades apologéticas del enfoque marxista en torno a la construcción del Estado nación, no es precisamente la intención expositiva de este acápite. Baste decir que esta corriente de pensamiento, en su afán por construir las bases doctrinarias y guías de acción política para concretar la revolución proletaria inminente, desplazó a segundo nivel teórico los problemas étnico-nacionales ya que éstos serían resueltos en la nueva sociedad socialista. Dicho de otro modo, asistimos a un tipo de concepción política y estratégica que relega el problema étnico y nacional a una posición secundaria y subordinada, y que al mismo tiempo expresa una forma de imaginario social sustentado en la idea de la comunidad homogénea socialista.

$\mathrm{Y}$ es que este horizonte utópico de futuro, levantado por sectores de izquierda ortodoxa, cerrada, acrítica y dogmática, veían en el proletariado a la única clase social capaz de conducir ese gran constructo societal. Así, el discurso y la práctica política de la izquierda comunista durante buenos años veía en el proletariado ${ }^{15}$ la única clase social que está en posibilidad de llevar adelante un proceso de lucha por la renovación de la sociedad. De esa forma, el proletariado aparece no sólamente como el agente sociopolítico destinado a cumplir una misión histórica, sino también como un personaje simbólico trascendental, una especie de salvador supremo que condensaría una suerte de mesianismo histórico.

Bajo ese esquema, los sectores marxistas impulsaron una lectura política que diluía la cuestión indígena en los derroteros clasistas a través de la fórmula: indios = campesinos o semiproletarios. De allí que las acciones organizativas emprendidas hayan asumido la forma de sindicatos campesinos o gremios clasistas agrarios, y con ello, la situación de los pueblos indios aparecía como un simple derivado de relaciones clasistas que actúan como determinantes, despojándolos de toda especificidad o, en el mejor de los casos, reducidos a fuerza auxiliar respecto a las supuestas «esencias» clasistas.

En el Ecuador, esta situación se vio claramente identificada en la dinámica de acción política del Partido Comunista desde los años cuarenta, época en que se funda la F.E.I. -Federación Ecuatoriana de Indios- ${ }^{16}$. Estas imágenes políticas de la izquierda ecuatoriana respecto de los sectores indígenas no variaron substancialmente con el pasar de los años y, aunque varios organismos gremiales del mismo perfil doctrinario incorporaron en sus plataformas de lucha aspectos referidos al rescate cultural y defensa tradicional de los grupos étnicos, lo cierto del asunto es que el gran ideario político de tranformación social siguió girando en torno a la falta de capacidad del indio para representarse por sí mismo ya que tenía que dejar de ser tal y acceder a la cultura, asimilarse simplemente a un trabajador ciudadano de preferencia asalariado, cuestión que paradógicamente, lo requería el mismo estado nacional y la sociedad blanco-mestiza en su afán homogeneizador. En otras palabras, estábamos asistiendo a una nueva faceta asimiladora con nuevo ropaje ideológico donde subyace la representación paternalista de la integración.

De esa peculiar manera entendieron la cuestión indígena los partidos de izquierda marxista, para quienes el indio no poseía una estrategia que le permitiese visualizar la transformación revolucionaria de la sociedad. La solución: aliarse incondicionalmente al proletariado para lograr su liberación definitiva ${ }^{17}$.

Este tipo de concepciones ideológicas guiaron en buena medida las principales luchas campesinas durante las décadas de los sesenta y setentas para conseguir la ejecución de la Reforma Agraria por parte del estado ecuatoriano. No obstante de esos logros políticos que transformaron el ámbito rural, caracterizado por la prevalencia de relaciones de trabajo serviles y retardatarias impuestas por los sectores hegemónicos y, sin desmerecer el papel organizativo desempeñado por los gremios y partidos de izquierda en ese proceso, resulta difícil negar que en su sistema conceptual primaron categorías e imágenes que consideraban al

15. A finales de los años cincuenta, la lectura política que hacía el Partido Comunista del Ecuador sobre la sociedad presentaba al país como dependiente del imperialismo y con rezagos feudales. Saad Pedro. «Lineamientos Programáticos de 1957» en: Obras escogidas, Ed Claridad, Guayaquil, 1977.

16. «La F.E.I. que es aún el sector campesino de la central sindical C.T.E. -Confederación de Trabajadores Ecuatorianos-, cuando nace, en 1944, lo hace precisamente bajo una concepción exclusivamente de clase, excluyendo una problemática étnica. Así lo imponía la filiación a la internacional comunista de la época, a la que se liga la nueva central. Por definición un campesino era indígena o socialmente un asimilado indígena, de ahí el nombre que tomó esa nueva organización campesina F.E.I. No era sin embargo la condición étnica la que convocaba a reagruparse en esta organización sindical» (Cursivas nuestras). Leon T. Jorge. «Las Organizaciones Indígenas: Igualdad y diferencia» en: INDIOS Abya YAla-Ildis, Quito, 1992. p. 381.

17. Basándose en la tesis marxista de que no pudiendo representarse deben ser representados a nivel estatal y nacional, los partidos de izquierda consideraron a los grupos indigenas como clases incapaces y subalternas. Posturas de esta índole las podemos encontrar en los trabajos de Fernando Velasco. Reforma Agraria y Movimiento Campesino e Indígena de la Sierra y el de Paola Silvo. Gamonalismo y Lucha Campesina. Para una ampliación de estos tópicos ver: Sanchez P. José. «Etnia, Estado y la forma Clase» en: Ecuador Debate N. 12, CAAP, Quito, 1986. 
indio como un compañero de segundo orden que debe ser conducido y representado en el gran proyecto de construcción socialista ${ }^{18}$.

A la postre, esta serie de errores conceptuales y políticos generarían una serie de procesos organizativos independientes por parte de sectores indígenas que, enarbolando la autonomía política y discursiva respecto a esa práctica paternalista de la izquierda, configuraron a inicios de los años ochenta una de las entidades políticas más movilizadoras y representativas desde el punto de vista de la identidad étnica.

Ahora bien, más allá de seguir enfatizando el carácter paternalista y redentor de la izquierda marxista, aspecto por demás conocido en diversos ámbitos latinoamericanos -y en ese asunto parecida a los liberales decimonónicos y partidos populistas-, lo importante es rescatar la idea en que se asume ese paternalismo. En efecto, al asumirse los sectores de izquierda como entidades representantes de los indios, reproducen, queriéndolo o no, la figura de un aparato indigenista no estatal que expresa y traduce -una ventriloquía política ${ }^{19}$ - las aspiraciones de determinados sujetos sociales, los indios, carentes de reconocimiento -legalidad y legitimidad-y, por ende, de discurso reconocido y acceso directo al sistema político.

En esa perspectiva, la izquierda ecuatoriana, al intervenir como una especie de organismo indigenista, una institución externa de ciudadanos blanco-mestizos que asumen la mediación de sujetos indios, reproduce aquellos aspectos ideológicos inherentes al Estado en su trato con sujetos coloniales: una población sin derechos reconocidos en el sistema jurídico y político del Estado-nación, cuya realidad aparece en recovecos de terceros intereses, en lenguajes dobles, en visiones deformadas de sí y de los otros ${ }^{20}$.

Así, en ese contexto de interpretaciones estructurales y al mismo tiempo, juego de representaciones realizadas a base de imágenes construídas sobre el indio, la izquierda marxista asumió la función de traducir las formas de lucha y reivindicaciones de los indígenas al orden simbólico de la ciudadanía, a conceptos de derecho de clase como trabajadores semiproletarios agrícolas o campesinos, y no como ciudadanos étnicos, como pueblos que exigen un reconocimiento colectivo en sus vínculos con el Estado-nación. Es más, el horizonte de futuro, identificado con la construcción de la nación socialista, volvía a presentar una dimensión imaginaria que diluía las especificidades etnoculturales de los pueblos indios para arribar a ese gran 'constructo' social.

\section{LA QUIEBRA DE LAS REPRESENTACIONES}

Junio de 1990, Agosto de 1994 y posiblemente las participaciones indígenas en las elecciones pasadas de estos años, constituyen verdaderos quiebres de los imaginarios nacionales respecto a los indios. Son épocas claves en la historia política ecuatoriana porque evidencian cambios profundos en las percepciones que se tenían sobre los movimientos indígenas. Varios partidos políticos, sectores sindicales, Estado y diversos componentes sociales, asistieron en este período, no solamente a la eclosión de un actor político con capacidad de interpelar a la sociedad, sino que la forma en que participaron, genera una ruptura del largo plazo con el que se habían construído imaginarios y representaciones sobre los indios y negros.

En ese juego, los indios, a más de las clásicas reivindicaciones -tierras, créditos, infraestructura, asistencia técnica, mejoras agrarias, participación en educación bilingue, etc.-, visualizó el problema étnico en la discusión sobre una reestructuración político-administrativa y constitucional del Estado ecuatoriano. El mérito de la propuesta indígena no radica solamente en el planteamiento de su autonomía y ciertas formas de autogobierno dentro de un Estado nacional único, sino que fundamentalmente evidencia la concreción de nueva forma de discursividad y práctica organizativa identitaria que estaba erosionando las bases ideológicas nacionales expresadas como comunidad imaginaria homogénea.

Tanto el Estado como la sociedad ecuatoriana en conjunto, si bien habían sido testigos de muchas transformaciones agrarias, revueltas campesinas, paros regionales, huelgas generales y acciones guerrilleras esporádicas, era la primera ocasión que asistían de forma directa a la interpelación del carácter «único» de la nacionalidad y de la formación nacional por parte de un sector social largamente excluído. $\mathrm{Y}$ es que esos grupos indios con su identidad diferenciada, en el largo proceso de toma de conciencia política de su «mismidad», tuvieron que pasar por un largo periplo organizativo que implicó dejar atrás toda una serie de paternalismos, representaciones e imágenes construídas por los «otros» sobre su carácter étnico. En ese sentido, la historia de una organización con alcance y convocatoria nacional y de características particularmente étnicas, ha tenido un extenso y complicado recorrido que ha privilegiado la especificidad de su carácter étnico ${ }^{21}$.

Por tal razón, las propuestas indígenas fracturan esa visión e imagen homogénea de la sociedad al crear un nuevo agente social, al impulsar postulados antes impensables e indecibles por falta de un discurso que los repre-

18. Esta en una de las constantes que caracteriza al pensamiento de la izquierda marxista ecuatoriana. En este tipo de acercamiento, el sistema político aparece como un epifenómeno de la estructura, la cual refleja una correspondencia automática entre las fuerzas productivas y las relaciones de producción como determinaciones unívocas de la superestructura política. Además, supone el otorgamiento de roles políticos implícitos a las clases, como reflejo de la base económica. De esa manera, la izquierda ofrecía un esquema reducido y estructuralista de la política. Bonilla Adrian. En Busca del Pueblo Perdido. Diferenciación y Discurso de la Izquierda Marxista en los Sesenta. FLACSO, Quito, 1991 p. 177.

19. La noción de ventriloquía política la tomo expresamente de Andrés Guerrero, con la salvedad de que la dirijo hacia las prácticas políticas y discursos de la izquierda marxista en Ecuador.

20. Guerrero Andrés. «La desintegración de la administración étnica en el Ecuador» en: Sismo Etnico en el Ecuador, Cedime-Abya Yala, Quito, 1993, p. 103.

21. Sobre este aspecto bien vale la pena un ejemplo ilustrativo. En 1969 se conforma la FECOPAN (Federación de organizaciones campesinas del Napo), la cual en 1979 se transforma en FOCIN (Federación de organizaciones campesinas e indígenas del Napo) y más tarde en FOIN (Federación de organizaciones indígenas del Napo). Este deslizamiento en el nombre de una organización es muy significativo del cambio operado en los discursos y en la conciencia del mismo movimiento indígena. Sanchez P. José. Presente y Futuro de los Pueblos Indigenas, Abya Yala, Quito, 1992 p. 11. 
sente auténticamente y por llevar al terreno del debate político, aspiraciones transformadoras del orden jurídicoadministrativo estatal nunca antes planteadas por movimiento social alguno desde la identidad étnica.

Como era de esperarse, los sectores hegemónicos y el estado fueron incapaces de absorber tal tipo de demandas, de considerar al «otro» en términos de dignidad y libertad, y de aceptar que los imaginarios y representaciones nacionales habían entrado en una profunda crisis operativa. Para ello se apeló a un tipo de discurso político que utiliza figuras deslegitimadoras y de enmascaramiento para contrarrestar las demandas indígenas. En definitiva, se recurrió a una serie de argumentaciones basadas en el carácter «único» de la nacionalidad, en la prevalencia de la identidad nacional, en la inconveniencia jurídica de los planteamientos y en la imagen del país como una comunidad homogénea ${ }^{22}$.

En ese contexto, resulta sorprendente que los partidos políticos ecuatorianos no hayan asumido una posición clara sobre la problemática indígena. Salvo exepciones, la toma de posiciones al respecto no es tan enigmática si la miramos desde una práctica política que tradicionalmente ha existido en el Ecuador, la cual expresa el carácter paternalista y excluyente de los partidos hacia el sector indio. En efecto, éstos organismos han privilegiado los espacios de integración ciudadana y las formas de representación sectorial por medio de redes clientelares como condición necesaria para la participación electoral de los indígenas. De esa manera, la especificidad de las demandas étnicas se diluyen en el marasmo de las prácticas partidarias o son asumidas en los programas de aquellos como ámbitos culturales que deben ser rescatados, exaltados e integrados en la sociedad nacional, vale decir, son prácticas políticas concretas que nos remiten a una suerte de indigenismo partidario ${ }^{23}$.

\section{FINAL}

Estos álgidos y complicados tópicos apenas han empezado a ser comprendidos cabalmente en el Ecuador. Mientras subsistan criterios estrechos y mentalidades cerradas, persistirá indefectiblemente un equívoco total acerca de las verdaderas intencionalidades políticas de los sectores indígenas y negros. Para aquella franja social, reducida, que se identifica con los actuales proyectos de inserción al mercado mundial y con democratizaciones limitadas, y que históricamente ha tratado de legitimar su juego de representaciones, las demandas indígenas contienen un sabor amargo difícil de digerir.

Hoy día podríamos decir que la sociedad ecuatoriana sufre la carencia de un proyecto de nación representativa La crisis de los macro referentes societales vistos como procesos de integración, la fractura de las representaciones e imaginarios elaborados sobre los indios y negros, las promesas incumplidas de la panacea neoliberal en materia económica y, los límites de participación impuestos por procesos de democratización que veladamente esconden relaciones sociales teñidas de racismo, muestran a un país que busca de manera azarosa nuevos horizontes de futuro.

22. Todas estas argumentaciones están recogidas por la prensa ecuatoriana desde 1990

23. En 1988, a propósito de las elecciones nacionales se realizó una investigación sobre participación indígena y proceso electoral. Los resul tados demostraron que el $47 \%$ de sufragantes indios no consideraban a ningún partido político como el representante de sus demandas e intere ses. CHIRIBOGa Manuel y Rivera Fredy. «Elecciones de 1988 y Participación Indígena» en: Ecuador Debate N. 17, CAAP, Quito, 1988.

\section{RESUMEN}

El conflicto indígena está a la orden del día en el nuevo panorama internacional en el cual las identidades regionales y étnicas cuestionan al Estado-Nación como ente integrador. En América Latina el fenómeno se hace palpable a través de lo indígena y su exclusión y dominación, posible en gran medida por el énfasis puesto en lo mayoritario (población mestiza). A lo minoritario, indígenas y negros, se le han creado algunos espacios paternalistas. El movimiento indígena, a partir de 1990 , ha ido cobrando voz y voto en el panorama político ecuatoriano, logrando así que el soporte de la identidad sobre la que se construyó lo nacional sea fracturado y se plantee la necesidad de adecuarlo a la diversidad étnica y cultural de esta sociedad.

Entre las políticas de tratamiento a lo indígena aplicadas en América Latina que el autor analiza se encuentran: los indigenismos, el neoindigenismo y el paternalismo clasista, cada una con una serie de principios y preceptos acordes a la ideología del grupo que la aplique.

El movimiento indígena ecuatoriano hace especial énfasis en la cuestión constitucional, política y administrativa del Estado, ante la cual plantea su autonomía y sus formas de organización identitarias, lo que lleva a la crisis de la política tradicional y plantea la necesidad de reformular el Estado, la Nación y la democracia en el país andino.

Palabras Claves: Ecuador - paternalismo - conflicto indígena - minorías - Estado- Nación.

\section{ABSTRACT}

Indigenous conflicts are characteristic of the new international situation. In this situation ethnic and regional identities question the nation-state as an integrating entity. In Latin America this phenomenon becomes apparent when we consider the indigenous groups and their exclusion and domination. This exclusion and domination is made possible by the emphasis that that mixed («mestizo») groups put on majoritary principles. For the minorities, a few paternalist spaces have been created. From 1990, the indigenous movment has gained voice and vote in the Ecuatorian political arena. In this way, the basis on which the national identity was created has been eroded, and it has been posed the need to adequate that basis to ethnic and cultural diversity. Among the policies used to deal with indigenous groups in Latin America are «indigenismo», and «class paternalism». Each policy relates to the ideologica principles of the group that develops it. Ecuatorian indigenous groups put special emphasis in constitutional, poiltical and administrative issues, and struggle for autonomy and identity organization. In this way they question traditional politics and pose the need reshape the state, the nation, and democracy.

Key words: Ecuador- paternalism-indigenous conflicts-minorities-nation-state. 


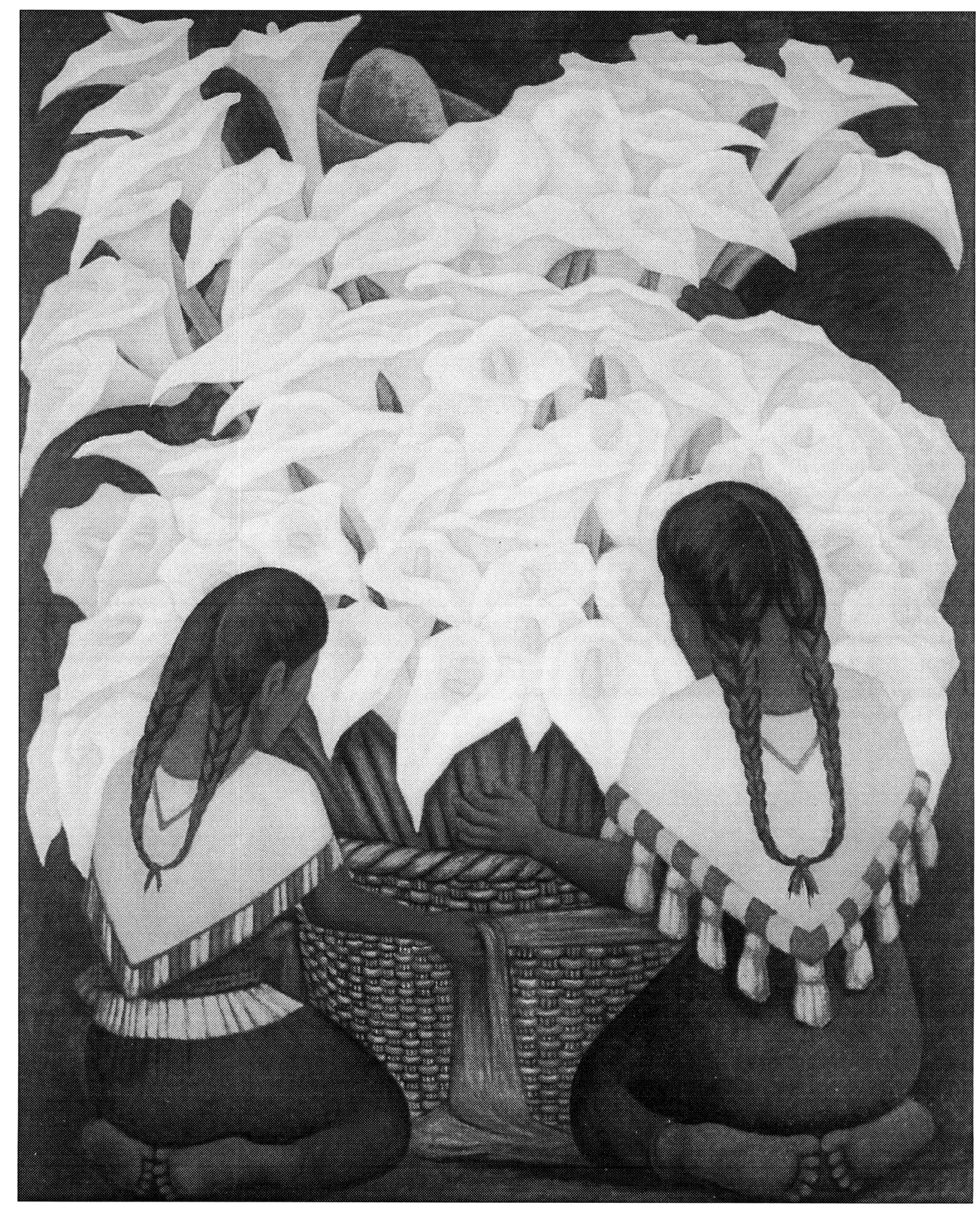

Diego Rivera, vendedoras de Alcatraces 